\title{
Guideline to Develop an Instructional Design Model Using Video Conference in Open Learning
}

\author{
https://doi.org/10.3991/ijet.v15i03.10842 \\ Narin Nonthamand \\ University of Phayao, Phayao, Thailand \\ narin.no@up.ac.th
}

\begin{abstract}
This research is a quantitative phenomenology study with objectives to (1) Synthesize literature related to teaching using video conference (2) Study opinions from experts' experience on the design of teaching using video conference and (3) Use as a guideline for the design of instructional video conference. The sample group in this research is 25 experts holding an academic position with at least 15 years of experience in teaching technology and education communication. The author uses the purposive sampling method. The data collection tool is an in-depth interview. The data is analyzed by the content analysis approach.

The research shows that the instructional design model using video conference consists of connected elements where each item is linked together and becomes an integral part of each other, namely (1) Teaching strategy (2) Preparation of instructor (3) Media and technology (4) Case study (5) Group process and (6) Idea sharing activity.
\end{abstract}

Keywords - Instructional design / Video conference / Open learning

\section{Introduction}

\subsection{Video-based open learning}

Nowadays, education is open to everyone. Each university designs and manages more open learning classes. Open learning is online learning that provides free curriculum where learners can conduct a self-learning approach with flexibility [1]. Such an approach allows learners to have access to endless content as desired. Much content is free, but some content is paid. However, being self-centered, this learning method also allows each student to join others, as well as the instructor, in the discovery of new knowledge. Additional knowledge is gained as a result of the interactions between learners, instructors, and materials. With flexibility in the class, this type of learning will mitigate and resolve issues and obstacles of learning, particularly those concerning expenses, traveling, time, location, and access. This includes issues with material structure. Furthermore, it will also promote and support lifelong learning [2], [3], [4]. The 
concept is based on distance education and distributed learning. Distance education includes distance learning and teaching while distributed learning includes open learning and flexible learning [5].

Sukhothai Thammathirat University is the only open learning campus in Thailand that implements the distance learning system at present. The concept is based on lifelong learning, mainly focusing on the quality of life of the public, enhancing education levels of all professions, and providing education to everyone. At Sukhothai University, classroom instructors and learners are not in the same physical location, but adequate resources are provided to remedy this interaction that was once considered by many to be a disadvantage. The learning materials are web-based through an electronic system, distance learning system, radio broadcast, video broadcast, television programs, DVDs, videos and online media [6]. Another channel for learning is on-air broadcasting, broadcasting via internet OTT (Over-the-Top), live programing for educational purposes, including social media. All these materials are provided to allow for convenient access to the content for learners.

Video is a digital media widely used among instructors in the self-learning system [7]. Video conference learning is used in the instructional design model including flipped classroom [8], online learning, massive open online courses (MOOCs) [9], [10], [11], an open-learning source using video for teaching or video conference where the video is material used as synchronous two-way communication. Video conference is a technology that allows learners to see and communicate with others from different locations. With video as learning material and a tool for creating activities, learners can also share files and, work together at the same time [12], [13], [14].

\subsection{Instructional design}

Instructors should design lessons based on video conference for open learning to suit the instructional activities of each objective by analyzing content. Thereafter, objectives can be determined and, activities will can be designed, utilizing proper tools for creating activities. Using systematic design processes in termed instructional design (often abbreviated ID), instructional design begins by first identifying the performance problems, without assuming that instruction is the cure-all remedy. If instruction is the most appropriate solution, then the design process can begin. The instructional design approach considers instruction from the perspective of the learner rather than from the perspective of the content. [15] In a broad sense, the term "technology" conceives any systematic application of scientific knowledge into practical issues. Accordingly, instructional technology can be defined as the systematic application of theories on learning and teaching, solving the practical issue of developing instructional systems. Thus, Instructional Systems Development (ISD) refers to the design of specific arrangements of resources and methods in order to improve learning. [16]. There are numerous instructional design models. The following are commonly accepted design models: ADDIE Model, a generic model for instructional design processes, which has five phases, (Analysis, Design, Development, Implementation, and Evaluation). the Dick and Carey Model, the Assure Model, the Kemp Design Model, the Gerlach-Ely Model, and the Seels \& Glasgow Model. [17], [18], [19], [20], [21], [22]. Instructors should 
have instructional design models for the use of learning management systems (LMS). Open learning has grown considerably in universities around the world. LMS can offer a great variety of channels and workspaces to facilitate information sharing and communication among participants in any given course [23]. Similarly, information and communication technologies (ICT) or eTwinning system brings together the educational community and can be summarised as follows:

- Increasing motivation and improving in the learning outcomes of students

- The development of electronic pedagogy

- Professional and pedagogical development of teachers

- Nurturing a culture of cooperation school units [24].

The unique characteristics of smart, mobile devices have great potential to enrich the teaching and learning experience. [25].

The lack of design of an instructional model using video conference may cause problems and obstacles in teaching. Thus, learners may lose a chance to exchange their experience, opinions, and knowledge. With the adequate design of instructional models using video conference, an instructor can guide learners to communicate amongst themselves and can create a learning format that enable learners to gain knowledge and discover new content together. [26], [27],[28], [29], [30].

The instructor can design the instructional model using video conference as a realtime event where lecturers' screens and files can be shared live with enabled conversation made via computer systems and many learners can join at the same time. In the past, using a video conference or remote meeting has been difficult as it required much equipment and expertise. However, at present, it is possible to arrange a video conference with smartphones, tablets, and other devices at all times via internet and a variety of conference calling applications available [31], [32], [33]. Learners can work together, communicate and exchange information in real time.

\subsection{Video conference design}

The enthusiasm of instructors and the following factors contributed to the success of the video conference:

- Pre-conference planning

- Setting clear objectives linking the curriculum and order of the subjects.

- Briefing learners on their expectations by discussing with them compliance, regulations, rules of the video conferencing

- Duration of the video conferencing

- Resolving technical issues by preparing equipment or software before the video conference

- The room used for a video conferencing should be quiet room.

In conclusion, instructors should prepare themselves. Learners should compare the material with other learners before class or speak with the instructor from time to time. 
The appearance of learners, as well as the background, should be proper when launching the video conference [34], [35].

Hence, using the structural design model with video conference in an open learning environment is vital. The instructor has to design the model in a systematic format with guidelines to suit the requirement of the learners to achieve an open-learning outcome that generates maximum benefit to learners. This model will also enhance the great learning channel.

\section{Purpose of the Research}

To synthesize literature related to structural models using video conference in an open learning environment gathered from experts in interviews. An in-depth look is taken at qualified opinions from experts with experience in the creating of lessons using video conference, which serve as a guideline for designing models using video conference in open learning.

\section{$3 \quad$ Research Method}

The research methodology is a quantitative phenomenology study. The researcher describes opinions from experts with experience with the objective of identifying and separating personal judgments and prejudices so that they don't affect the process of analysis. Afterwards, the researcher proceeds with the content analysis. This refers to the process wherein the researcher lists each of the relevant quotes of the studied topic and gives them equal value with regard to the expressions of the group. Questions that are subsequently asked: "What are the participants saying?" "What are the relevant topics expressed by the research participants?" The researcher then groups the relevant topics into units of meaning and writes textual and structural descriptions. Finally, according to the textual and structural analysis, the researcher proceeds to identify the essence of the phenomenon; the common elements repeated in each of the researched participants. [36]

\subsection{Participants}

The sample group for this research is the 25 experts with at least 15 years of experience as an instructor, experience in technologies and scholarly communication, or experience with the development of instructional design using video conference or distance learning. Other qualifications include: being an instructor in higher education, obtaining a degree in the Faculty of Education Sciences or related majors, having conducted research or composing textbooks in related fields, or holding a specific academic position belonging to the Office of the Higher Education Commission. Fields of experts are categorized as follows:

- 7 Professors of Instructional design

- 7 professors of Open learning or distance learning 
- 11 professors of Education technologies and communication with a total 25 professors [37], [38]. The researcher uses purposive sampling.

\subsection{Applied tools for data collection}

The instrument used in the study was a structured in-depth interview and an openended interview. The questions were developed based on synthesized research and literature related to the instructional model using video conference. The questions for the in-depth interview are divided into three parts: Part 1, general information of interviewee, Part 2, opinions on an instructional model using video conference, and Part 3, instructional design using video conference. A specialist in Education Technology and Communication, (in tandem with 5 experts measured and evaluated the content validity with 4 items, the index of Item-Objective Congruence (IOC) which was used to find the content validity and to evaluate the items of the questionnaire based on a score range from -1 to +1 . In this research the $\mathrm{IOC}=0.99$.

\section{Data Collection and Analysis}

The qualitative data was collected by in-depth interview with the experts to make an in-depth face-to-face interview in order to collect qualitative data. Before the interview, a researcher obtained permission to record voice during the interview. If an expert refused the voice recording, the researcher had to write down topics of conversation during the interview, which the expert reviewed before the data analysis. The interview covered each prepared topic. The data was reviewed by a content analysis method along the following steps:

- Distinguishing the difference of definitions (meanings) or compare the similarity

- Data collection referred to finding coded similarities of data obtained from the interview and transcript, which found the relation of the speech and code hidden in the definitions

- Analysis aimed to find out how each part of the code correlated with one another and with the phenomenon.

\section{$5 \quad$ Results}

The results of the research and literature related to the structural model using video conference is as follows:

- Use as a tool for two way communication

- Use to support learning

- Use for arranging learning activities

- Use as a tool in collaborative learning. 
Thereafter, the researcher brings the topics forward to create the in-depth interview questions. This concurs with [39], [40], [41], [42], [43], [44], [45], [46], [47], [48].

According to the study based on the experience of experts related to structural design model using video conference, the results of the analysis show that learning with video conference is associated mainly with learning strategy, communication, group process, idea sharing activity, followed by interaction and communication and preparation of instructor. The analysis result is presented in the figure as below.

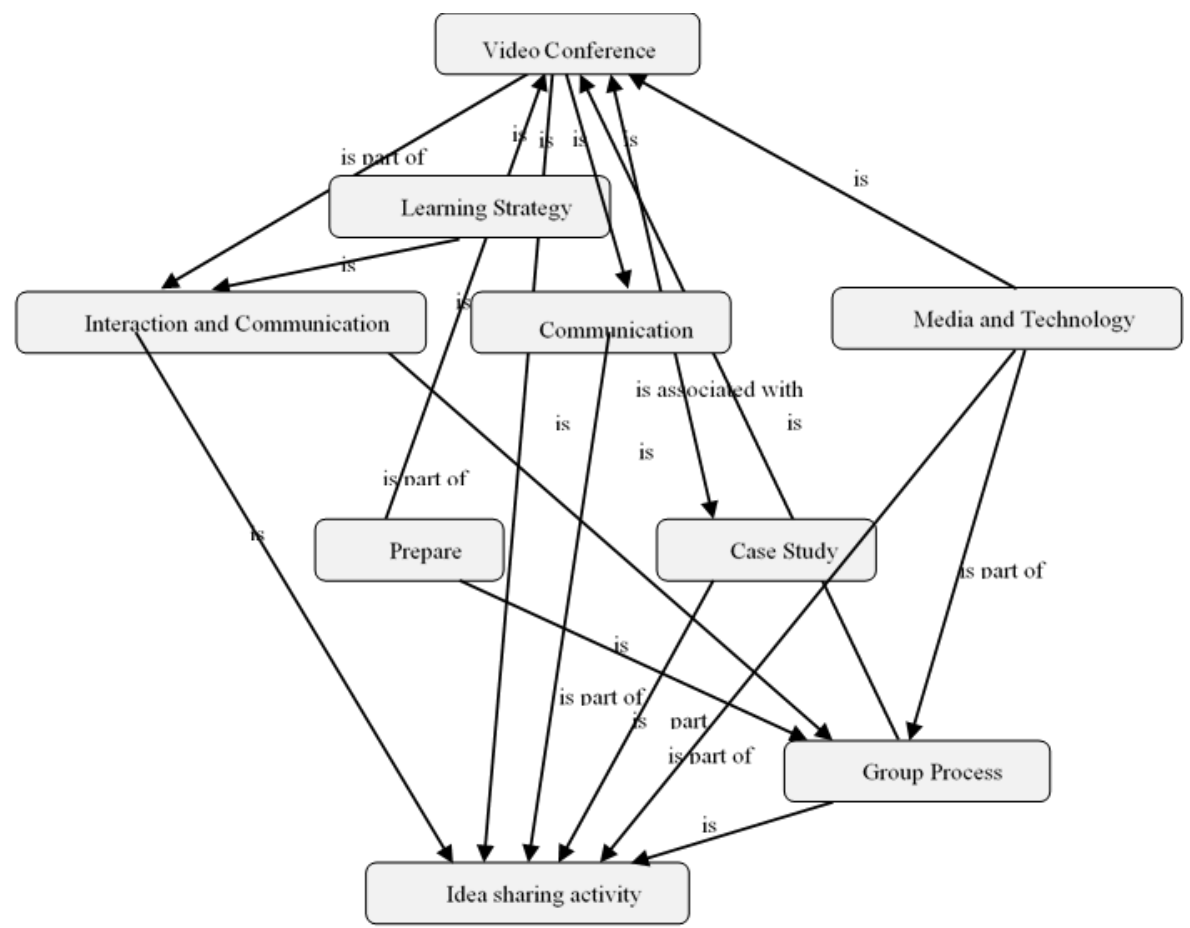

Fig. 1. Analysis result of elements of structural design using video conference in open learning

\section{Summary and Conclusion}

The guideline of structural design using video conference is associated with various elements. They are as follows:

Instructional design using video conference: The instructor should emphasize the learning strategy, reaction, and communication via video conference. In this case, the video conference is used as a medium and technology in learning management based on group procedures where learners can exchange their opinions, the preparation by the instructor has to be considered, elements which the instructor should study to guide the design which include learning strategy, communication, group process, idea sharing activities, interaction and communication and preparation of instructors. 


\subsection{Learning strategy}

1) Instructors should realize the importance of exchanging opinions, discussions, and conversations in order to create inspire knowledge among learners. The instructor may also apply the Social Constructivist theory to design learning activities using video conference.

2) Instructors should emphasize the design of learning activities by using various group processes. In other words, design the learning procedures where all learners react and communicate among each other in order to achieve the learning target set forth in the video conference.

3) Instructors should select various techniques, i.e.:

(a) Techniques for brainstorming - to practice creative thinking where all learners are free to seek possible solutions

(b) Techniques for visualizing ideas - converting abstract to concrete ideas

(c) Techniques for examining ideas - to consider ideas for further practice. This technique will lead learners towards creative problem resolving based on various ideas created during brainstorming. The solutions or answers from learners should vary and only one answer is incorrect.

4) Using video conference in the classroom in order to brainstorm with learners allows learners to work together and create a relationship. These will enable them to overcome inhibition and to express their opinions. Instructors may ask learners to introduce themselves before starting the class and share opinions in order to perform assessments. Learners should also express their expectations for the class and instructor as well.

5) Using video conference to summarize learning content after class, instructors can design activities that will enable learners to ask questions in real-time. This is two-way communication where instructors should observe learners while using video conference.

6) Using video conference is suitable for group activities where instructors will present problems, events, or topics for learners to share their opinions on, as well as to discuss the relating material. This step focuses on exchanging opinions among learners.

7) Using video conference for presentation: An instructor's screen is shared with learners. In the meantime, an instructor may open a lecturing document in clear view of the learners, similar to the process for brainstorming.

8) Using video conference with other videos, video-on-demand, or live video before having a video conference for activity: In this element, video conference is a learning strategy where instructors can begin to outline their lesson plans and add activities. They can decide how each segment will be completed. This necessitates consistent use of the Dick and Carey Instructional Design Model in developing instruction strategy processes [49]. 


\subsection{Communication}

1) Instructors should analyze learners before or at the beginning of the video conference, because the communication characteristics of learners are different. This includes a personal learning network that will allow for communication during the video conference.

2) Instructors should analyze learners' skills and abilities in using digital learning tools, such as information technology and media. This is a valuable skill in the 21 st century.

3) Instructors should have skills and abilities in using tools for online learning.

4) The wording in communication should be in a positive way that creates familiarity with learners so that that they are willing to express their opinions in each activity.

5) Instructors should prepare alternative communication channels or tools other than video conference, such as social media applications which learners are familiar with and regularly use.

6) Instructors should prepare hardware and software required for video conference, including information for learners on how to use the software.

7) Instructors should inform learners about conditions of usage. For example, software may need to be installed prior to the lesson.

8) Instructors should know how to use various software, such as screen sharing and file sharing during the conference.

9) Using video conference as a communication tool is two-way communication where users can express their emotions and feelings.

10) Video conference should be available on mobile phones for ease of use.

11) During the video conference, learners and instructors should consider their appearance, nice background, and background noise. The location for launching a video conference should be quiet. Hence, everyone should arrange a proper environment for video conference while open learning.

In this element, video conference is communication that can express emotion, feelings, and motivations, like those reported by [50] the aforementioned results, suggesting that teachers with good communication skills will create a more successful teaching and learning environment for students.

\subsection{Group process}

1) Instructors should bring up problems or simulations of events related to the subject to encourage the exchange of opinions.

2) Instructors should focus on all learners in a video conference, as it is a learning process that highlights the learners and provides and inclusive experience where everyone has an equal chance to attend the activity.

3) Instructors should manage the learning environment in a way where learners will gain the most from opinions shared amongst themselves. The group of learners provides a significant source of knowledge. This will enable learners 
to understand issues, gain knowledge, and adapt and adjust with the other students.

4) Instructors should arrange online, group-related activities so that all learners will get to know each other before the class. The activity can be arranged through various tools. For example, a short video conference for introductions before starting the video conference class may be necessary. The topic of discussion in the introduction video conference could be hometowns or birthdays. These questions allow learners to express stress or anxiety in a technique called Ice Breaking, which is aimed at creating familiarity and encouragement among learners.

5) Instructors should sometimes allow time and space for learners to build trust and respect amongst each other, and to create bonds within the learning group. These factors will subsequently lead to acceptance amongst each other, and learners will not be intimidated to share their thoughts

6) Instructors should be careful when dividing learning groups. Instructors should diversify groups based on age, gender, and occupation in order to create a variety of group members. Once the learners have grouped themselves, they will start getting to know each other, though not in a forced manner. Subsequently, when a certain activity is completed, there may be a rotation of group of members among the different groups.

7) The Group Process has significant driving force on the learning process. As the saying goes, "Two heads are better than one." However, the point is to extract real ability and opinions of learners and thus will generate the power of brainstorming.

8) The Group Process will create new knowledge elements based upon various experiences among learners. Experiences play vital roles in the Group Process.

9) Instructors should address the importance of befriending classmates. Help and support from classmates can contribute to the success of gaining of knowledge by sharing opinions and ideas.

In this element, video conference is a group process activity by design. Instructors should design activities with group processes. Consistent use of the Gerlach and Ely Design Instructional Design Model helps strategize the process. The choices here can range from the expository, more traditional approach of the teacher presenting all the information and activity design, to the inquiry approach where the instructor is a facilitator helping students discover [51].

\subsection{Idea sharing activity}

1) Instructors should design activities that allow learners to share their ideas. This activity can be divided into three steps; before, during, and after the activity

2) Before the activity, instructors should let learners introduce themselves formally and straightforwardly via video conference. Learners can also record a video introducing themselves to send to the other learners. They can ask questions related to the subject and activity. 
3) During the activity, instructors should study the technique of group process and apply to future objectives using video conference.

4) Instructors should design learning activities based on the encouragement of self-discovery and creation. Instructors manage the class, facilitate the learning process, and support learners to find and discover answers from a variety of opinions. Thus, learners will be able to analyze themselves upon continuous reaction during the learning activities.

5) Instructors should present examples of cases or situations and allow learners to discuss, criticize, and share comments. Sometimes, instructors may consider inviting specialists or a person with experience related to the learning subject to join the class where learners will gain additional knowledge from the opinions of such specialists or person(s) with experience.

6) The content brought to learning activities should be modern or contemporary which learners can adapt to their daily lives.

7) Instructors should consider the time frame of each activity, since each learner's schedule is different. It is recommended that they let learners decide the timeframe they will be available.

8) Instructors should design an activity that focuses on sharing opinions, emotions, and feelings. Thereafter, the learning in each activity should be recorded.

9) Instructors should design activities that link the knowledge of learners together. The activity should be divided into steps.

10) The learning activity should be challenging for learners and the learners' abilities. Instructors should design an evaluation for each learning activity in order to evaluate learners.

11) Instructors should design, support, motivate and encourage learners during the class.

In this element, video conference is an idea sharing activity of group process. Instructors should design activities with the idea of shared activities. It helps learners to clarify their own understanding and provides an opportunity for them to question others. Consistent use of the Kemp Instructional Design Model in design instructional strategies is helpful to enable individual learners to master the content and achieve the desired learning outcomes so that each learner can master the objectives process [52].

\subsection{Interaction and communication}

1) Instructors should focus on interactions amongst learners and between learners and instructor mainly in order to motivate the exchange of opinions.

2) Instructors should address the importance of communication between groups and within groups of learners. The reason being the length of the video conference in an open-learning environment is short, therefore less time for interaction and communication among each other. Instructors can provide encouragement by assigning work in groups.

3) Instructors should have alternative tools as a communication channel between learners and instructors. 
4) Instructors should design learning activities and motivate learners throughout the video conference class. Each duration is to be 45 minutes or between 1 hour and 30 minutes to 2 hours. The time frame should be set, for example, 13.00 - 14.30 hours. Assign 10 minutes before class so that learners can prepare themselves.

5) Instructors select video conference for summarizing and exchanging opinions. Learners should study the subject prior to the conference so they can ask any questions immediately.

6) Interaction and communication focused on the learner.

7) Instructors should analyze learners based on communication and interaction skills because these directly affect interaction and communication in the class.

8) Instructors should provide advice or consultation about video conference technology as some students may not be familiar.

In this element, video conference is used for interaction and communication between students in open learning environments. Consistent [53], three-part interaction in distance education scheme includes: (1) learner-instructor, (2) learner-learner, and (3) learner-content interaction. In accordance with the concept of Constructivism Theory, knowledge is generated or constructed by the learner through his or her interactions. Learners build meaning and make sense of their world through interacting with their surroundings. Social constructivists believe that learning occurs through social dialog and shared experiences [54].

\subsection{Preparation of instructors}

Learning with video conference can be divided into 3 significant steps. They are as follows:

1) Pre-learning activities include the testing of system of software, preparing systems or software, setting objectives and schedule, setting pre- and post-learning activity, describing activity details

2) Activities during the lesson include, activity launching

3) Post-activity procedures include, asking questions, exchanging opinions, and summarizing content.

In some cases, instructors may arrange workshops which emphasize practicing amongst learners with an aim to enhance skills and to enable them to visualize actual practice. Procedure description is shown in the Figure below. 


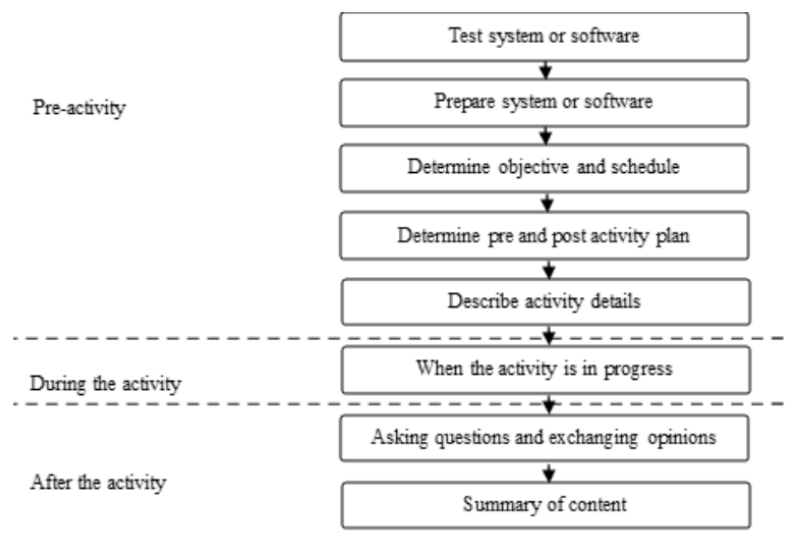

Fig. 2. Preparation of instructors in learning with video conference

Each procedure is described below:

1) Testing the system or software: Video conference is classified by its use as a web-based video conferencing and room-based conferencing. In an openlearning environment, instructors should select web-based video conferencing for the convenience of learners and select tools available on the various websites, including applications on mobile devices. Video conference requires a camera, microphone, and speaker.

2) Prepare alternative systems or software: In case of an error in the primary software or system; an instructor can use the alternative one immediately. The additional device will ensure the smooth and continuous flow of video conference learning.

3) Determine objectives and schedule: Instructors should set the objectives of the video conference lesson in each session and design a flexible schedule for learners. For example, the first step is preparation for the lesson. Next, learners can exchange opinions and summarize the lesson via video conference

4) Determine pre- and post-lesson activities: Instructors should design activities for before and after the video conference. For example, instructors may present content, topics, ideas, or slide shows (PowerPoint presentations) to learners before the video conference. After the video conference, instructors may design additional activities.

5) Describe activity details: Instructors should specify activities and roles of everyone in all steps. However, such conditions can be adjusted to suit the situation or class. Instructors should set roles of learners so that they can prepare themselves before attending the video conference.

6) Activity: Instructors should run the activity in accordance with the design and plan set forth by the objective of each activity. Instructors lead the conversation and encourage learners to exchange opinions, supervise the conversation so that it remains within the scope of the lesson, and link conversations and topics based on the opinions of all learners. In each activity, instructors should 
try to encourage learners to express their opinions and instructors should carefully listen to all opinions.

7) Question Asking: Share and exchange opinions: Instructors should facilitate this sharing in class. In addition to stimulating learners to concentrate and ask questions, instructors should also be able to answer their questions. Such interaction will allow instructors to evaluate learners. A compelling practice is to support them by responding with a positive compliment in order to maintain a good relationship. Instructors should also show learners that he/she is learning new material along with them and that the exchange of opinions is essential in the classroom.

8) Summary: Instructors will summarize a subject or topic of discussion, analyzing the main idea, reasons, and background thereof. Furthermore, instructors should advise learners on what they have learned from attending the video conference class. After the summary of subject, instructors may create an activity to carry on the learning in order to allow learners to review and create an additional-experiences in the aforementioned subject. This will be a new experience for them.

The instructors should design an instruction model which follows a clear and concise methodology in compliance with ADDIE (Analysis, Design, Development, Implementation, and Evaluation) and integrate each element: learning strategy, communication, group process, idea sharing activities, interaction, communication and preparation of instructors in the video conference instruction model.

For further research, one can study and experiment with the video conference instructional design model, which can be developed by an instructor and used in an open-learning environment, eLearning software, or massive open online course (MOOC).

\section{$7 \quad$ References}

[1] Fasihuddin, H., Skinner, G., \& Athauda, R. (2017). Towards adaptive open learning environments: Evaluating the precision of identifying learning styles by tracking learners' behaviours. Education and Information Technologies, 22(3), 807-825. https://doi.org/10. 1007/s10639-015-9458-5

[2] Burge, E. J., \& Frewin, C. C. (1985). Self-Directed in Distance Learning. In Husen, Torstin: The International Encyclopedia of Education. New York: Pergamon Press Inc.

[3] Holmberg, B. (1989). Theory and practice of distance education. London: Routledge.

[4] Mugridge, I. (1991). Distance education and the teaching of science. Impact of Science on Society, 41(4), 313-20.

[5] Tella, S. (1997). An" Uneasy Alliance" of Media Education and Multiculturalism, with a View to Foreign Language Learning Methodology. Ole Publications 4: Department of Teacher Education.

[6] Sukhothai Thammathirat University. (2019). STOU Distance Learning System. Retrieved from https://www.stou.ac.th/main/en/distance.html.

[7] Mitrovic, A., Dimitrova, V., Lau, L., Weerasinghe, A., \& Mathews, M. (2017). Supporting constructive video-based learning: requirements elicitation from exploratory studies. Paper 
presented at the International Conference on Artificial Intelligence in Education. https:// doi.org/10.1007/978-3-319-61425-0 19

[8] Kurtz, G., Tsimerman, A., \& Steiner-Lavi, O. (2014). The flipped-classroom approach: The answer to future learning? European Journal of Open, Distance and E-Learning, 17(2), 172182.

[9] Guo, P. J., Kim, J., \& Rubin, R. (2014). How video production affects student engagement: an empirical study of MOOC videos. Paper presented at the Proceedings of the first ACM conference on Learning@ scale conference. https://doi.org/10.1145/2556325.2566239

[10] Luo, Y., Li, J., Zhu, J., Xie, Z., Hu, X., Zhou, G., \& Xiao, Z. (2018). Study on Construction Process of MOOC Course.

[11] Vieira, I., Lopes, A. P., \& Soares, F. (2014). The potential benefits of using videos in higher education. Paper presented at the Proceedings of EDULEARN14 Conference.

[12] Becta. (2003). What the research says about digital video in teaching and learning. Retrieved from: http://39lu337z5111zjr1ilntpio4-wpengine.netdna-ssl.com/wp-content/uploads/2016/ 04/wtrs_15_digital_video.pdf

[13] Borup, J., West, R. E., \& Graham, C. R. (2013). The influence of asynchronous video communication on learner social presence: a narrative analysis of four cases. Distance Education, 34(1), 48-63. https://doi.org/10.1080/01587919.2013.770427

[14] International Education and Resource Network: iEARN. (2018). VIDEO CONFERE NCING GUIDE: BUILDING RELATIONSHIPS THROUGH VIDEO CONFERE NCING. Retrieved from: https://iearn.org/uploads/mdia/00/00/09/68/96855_Video_conference Guide 2.pdf

[15] Morrison, G. R., Ross, S. J., Morrison, J. R., \& Kalman, H. K. (2019). Designing effective instruction, 8th Edition: Wiley.

[16] Seel, N. M., Lehmann, T., Blumschein, P., \& Podolskiy, O. A. (2017). Instructional design for learning: Theoretical foundations: Springer. https://doi.org/10.1007/978-94-6300-941-6

[17] Arshavskiy, M. (2013). Instructional Design for ELearning: Essential guide to creating successful eLearning courses. CreateSpace Independent Publishing Platform.

[18] Jonassen, D. H. (1997). Instructional design model for well-structured and ill-structured problem-solving learning outcomes. Educational Technology: Research and Development, 45(1), 65-95.

[19] Moore, D., Bates, A., \& Grundling, J. (2002). Instructional design. Skills Development through Distance Education, 71.

[20] Naidu, D. (2013). Instructional design models for optimal learning - Handbook of distance education. NY: Routledge New York.

[21] Richey, R. C., Klein, J. D., \& Tracey, M. W. (2011). The instructional design knowledge base: Theory, research, and practice: Routledge.

[22] Seels, B., \& Glasgow, Z. (1990). Exercises in instructional design. Merrill Publishing Company.

[23] Papadakis, S., Kalogiannakis, M., Sifaki, E., \& Vidakis, N. (2018). Access moodle using smart mobile phones. A case study in a Greek University. In Interactivity, Game Creation, Design, Learning, and Innovation (pp. 376-385): Springer. https://doi.org/10.1007/978-3319-76908-0_36

[24] Papadakis, S. (2016). Creativity and innovation in European education. Ten years eTwinning. Past, present and the future. International Journal of Technology Enhanced Learning, 8(3-4), 279-296.

[25] Papadakis, S. (2018). Evaluating pre-service teachers' acceptance of mobile devices with regards to their age and gender: a case study in Greece. International Journal of Mobile Learning and Organisation, 12(4), 336-352. 
[26] Dreamson, N. (2017). Online collaboration in design education: an experiment in real-time manipulation of prototypes and communication. International Journal of Art \& Design Education, 36(2), 188-199. https://doi.org/10.1111/jade.12079

[27] Osterman, P. (2016). Video conference as a tool for enhancing student collaboration. Politehnika i dizajn, 4(04).

[28] Roberts, R. (2009). Video Conferencing in Distance Learning: A New Zealand Schools' Perspective. Journal of Open, Flexible, and Distance Learning, 13(1), 91-107.

[29] Sorokin, R., \& Rougier, J.-L. (2018). Video conference in the fog: an economical approach based on enterprise desktop grid. Annals of Telecommunications, 73(5), 305-316. DOI:10. 1007/s12243-017-0613-4

[30] Tomadaki, E., Quick, K. A., \& Scott, P. J. (2008). Videoconferencing in Open Learning. Journal of Interactive Media in Education.

[31] Barolo, P. (2018). Zoom Expands Communications Platform: Zoom Voice, App Marketplace, Zoom Rooms Partnerships \& More. Retrieved from https://blog.zoom.us/wordpress/2018/10/11/zoom-expands-communications-platform-zoom-voice-app-marketplacezoom-rooms-partnerships-more/. https://doi.org/10.7551/mitpress/1813.003.0004

[32] Lawson, T., \& Comber, C. (2010). Videoconferencing in English schools: One technology, many pedagogies? (Vol. Pedagogy and Education). https://doi.org/10.1080/1475939x.20 $\underline{10.513764}$

[33] Unuth, N. (2018). 7 Benefits of Video Conferencing. Retrieved from https://www.lifewire. com/benefits-of-video-conferencing-4108480

[34] Moore, M. G. (2013). Handbook of distance education: Routledge.

[35] Lawson, T., Comber, C., Gage, J., \& Cullum-Hanshaw, A. (2010). Images of the future for education? Videoconferencing: A literature review. Technology, Pedagogy and Education, 19(3), 295-314. https://doi.org/10.1080/1475939x.2010.513761

[36] Creswell, J. W., \& Poth, C. N. (2017). Qualitative inquiry and research design: Choosing among five approaches: Sage publications.

[37] Creswell, M. W., Bolton, G. L., Hodges, J. C., \& Meppen, M. (1998). Combinatorial synthesis of dihydropyridone libraries and their derivatives. Tetrahedron, 54(16), 3983-3998.

[38] Morse, J. M. (1994). Designing funded qualitative research (N. K. Denzin \& Y. S. Lincoln Eds. 2nd ed.). Thousand Oaks, CA: Sage.

[39] Adewale, A. A., John, S. N., \& Ike, D. U. (2014). Design and Implementation of a Virtual Machine Video Conferencing Application. International Journal of Engineering And Computer Science, 3(3), 5054-5063.

[40] Anastasiades, P. S., Filippousis, G., Karvunis, L., Siakas, S., Tomazinakis, A., Giza, P., \& Mastoraki, H. (2010). Interactive Videoconferencing for collaborative learning at a distance in the school of 21st century: A case study in elementary schools in Greece. Computers \& Education, 54(2), 321-339. https://doi.org/10.1016/i.compedu.2009.08.016

[41] Dreamson, N. (2017). Online collaboration in design education: an experiment in real-time manipulation of prototypes and communication. International Journal of Art \& Design Education, 36(2), 188-199. https://doi.org/10.1111/jade.12079

[42] Klenke, H. A. (2014). The effects of interactive videoconferencing on elementary literacy: collaborative learning environment.

[43] Lawson, T., \& Comber, C. (2014). Videoconferencing and learning in the classroom: the effects of being an Orphan Technology?

[44] Osterman, P. (2016). Video conference as a tool for enhancing student collaboration. Politehnika i dizajn, 4(04).

[45] Panagiotakopoulos, C., Tsiatsos, T., Lionarakis, A., \& Tzanakos, N. (2013). Teleconference

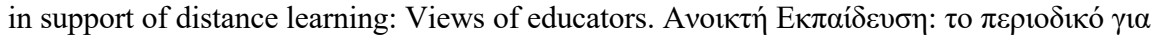




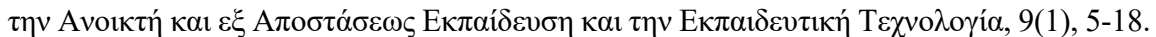
https://doi.org/10.12681/jode.9806

[46] Roberts, R. (2009). Video Conferencing in Distance Learning: A New Zealand Schools' Perspective. Journal of Open, Flexible, and Distance Learning, 13(1), 91-107.

[47] Sorokin, R., \& Rougier, J.-L. (2018). Video conference in the fog: an economical approach based on enterprise desktop grid. Annals of Telecommunications, 73(5), 305-316. https:// doi.org/10.1007/s12243-017-0613-4

[48] Tomadaki, E., Quick, K. A., \& Scott, P. J. (2008). Videoconferencing in Open Learning. Journal of Interactive Media in Education.

[49] Dick, W., Carey, L., \& Carey, J. O. (2005). The systematic design of instruction. Allyn \& Bacon Publisher. United States.

[50] Duta, N., Panisoara, G., \& Panisoara, I.-O. (2015). The Effective Communication inTeaching. Diagnostic study regarding the academic learning motivation to students. Procedia Social and Behavioral Sciences, 186, 1007-1012. https://doi.org/10.101 6/j.sbspro.2015.04.064

[51] Gerlach, V.S., \& Ely, D.P. (1980). Teaching \& Media: A Systematic Approach (2nd ed.). Englewood Cliffs, NJ: Prentice-Hall Incorporated.

[52] Morrison, G. R., Ross, S. M., Kemp, J. E., \& Kalman, H. (2010). Designing effective instruction. John Wiley \& Sons.

[53] Moore, M. G. (1989). Editorial: Three types of interaction. The American Journal of Distance Education, 3(2), 1-6.

[54] Jonassen D., Davidson, A., Collins, M., Campbell, J., \& Haag, B.B. (1995).

Constructivism and computer-mediated communication in distance education. The American Journal of Distance Education, 9(2), 7-26.

\section{Author}

Narin Nonthamand is a lecturer at the Department of Educational Technology, School of education, University of Phayao, Thailand. He received the B.Ed degree in Educational Technology from Burapha University, M.Ed. degree \& Ph.D degree, in Education Technology and Communications from Chulalongkorn University. His research interests include instructional design, video-based learning, open learning, online learning and MOOCs.narin.no@up.ac.th

Article submitted 2019-05-10. Resubmitted 2019-08-20. Final acceptance 2019-08-21. Final version published as submitted by the authors. 